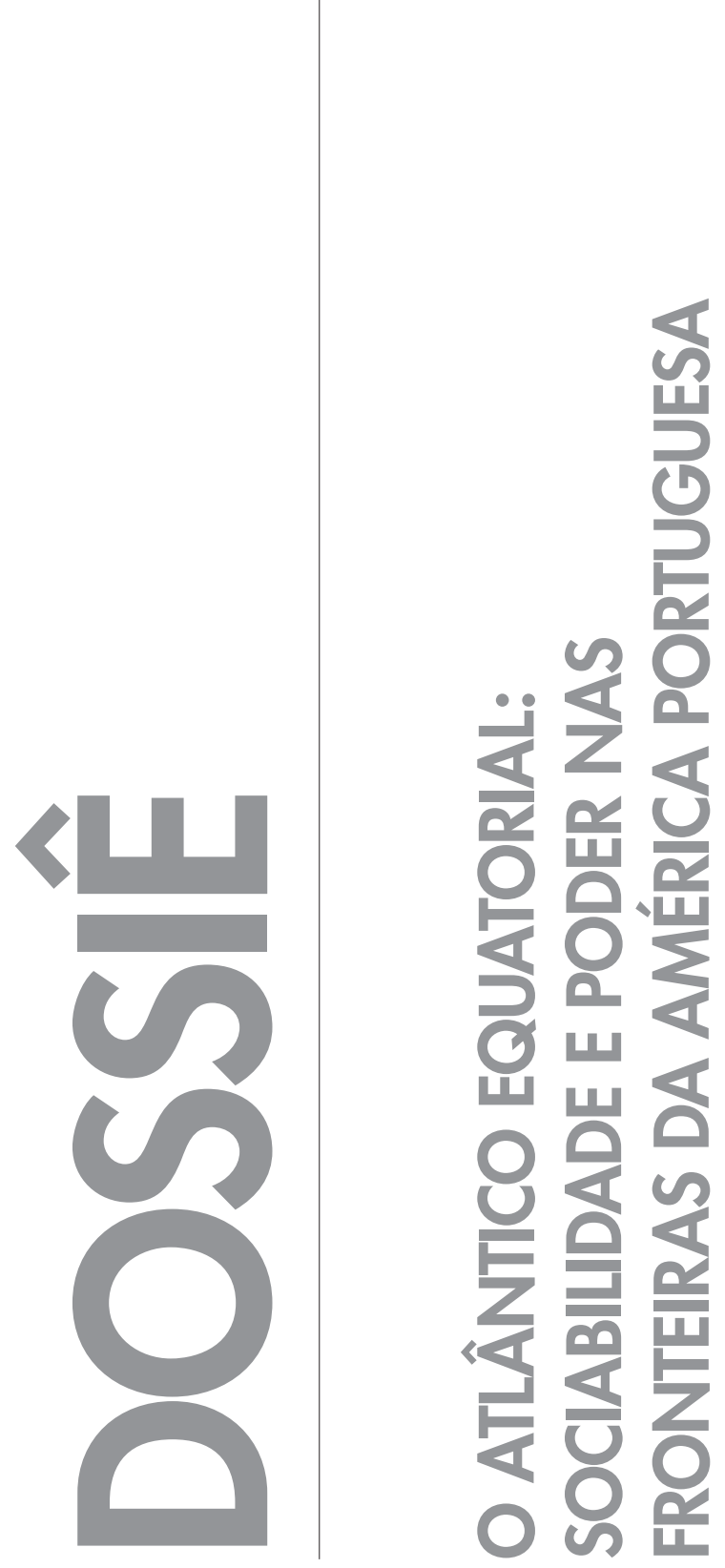




\title{
O ATLÂNTICO EQUATORIAL: \\ SOCIABILIDADE E PODER \\ NAS FRONTEIRAS DA \\ AMÉRICA PORTUGUESA
}

\author{
Patrícia Melo Sampaio' \\ Mauro Cezar Coelho²
}

A Amazônia portuguesa compreende uma área singular no conjunto das possessões ultramarinas lusitanas. Área de colonização tardia, cuja ocupação teve início cerca de um século após a conquista do litoral americano, ela conheceu relações sociais e políticas que demandam modelos explicativos próprios.

\footnotetext{
1 Possui mestrado (1994) e doutorado em História (2001) pela Universidade Federal Fluminense e pós-doutorado pela Unicamp (2013). Desde 1986 é professora do Departamento de História da Universidade Federal do Amazonas. Atua nas áreas de história indígena e do indigenismo, história colonial/imperial (Brasil e Amazônia) e história da escravidão africana na Amazônia. É líder do grupo de pesquisa História Indígena e da Escravidão Africana na Amazônia (Hindia) e pesquisadora do Núcleo de Pesquisa em Política, Instituições e Práticas Sociais - Polis. Participa do mestrado de História (PPGH/Ufam) e do mestrado/doutorado em Sociedade e Cultura na Amazônia (PPGSCA/Ufam) (Fonte: Plataforma Lattes/CNPq).

2 Possui graduação e bacharelado em História pela Universidade Federal Fluminense (1994), graduação e licenciatura em História pela Universidade Federal Fluminense (1994), mestrado em História Social da Cultura pela Pontifícia Universidade Católica do Rio de Janeiro (1996) e doutorado em História Social pela Universidade de São Paulo (2006). Atualmente é coordenador de curso de licenciatura em História/PARFOR da Universidade Federal do Pará e professor adjunto na mesma universidade. Tem experiência na área de História, com ênfase em História colonial e ensino de História, atuando principalmente nos seguintes temas: Amazônia colonial, história indígena e do indigenismo, história da ciência, história da educação e ensino de história (Fonte: Plataforma Lattes/CNPq).
} 
A sociedade colonial emergente nesta área da América portuguesa foi profundamente demarcada pelas relações mantidas com os povos indígenas ali estabelecidos. Povos diversos, que fique bem entendido, com demandas e agendas distintas, não raro discordantes. Da mesma forma, as relações econômicas emergidas naquela região guardam uma relativa singularidade, se comparadas às outras áreas do império. As atividades extrativistas cedo assumiram a condição de atividade estruturante em larga parcela do território. Elas não reinaram, no entanto, exclusivas. A criação de gado, a monocultura da cana, a agricultura de alimentos (especialmente da mandioca) e as atividades de beneficiamento (da mandioca, da pesca, do extrativismo) conviveram com a produção de canoas e de um sem número de artefatos necessários ao dia-a-dia da colônia.

Outra dimensão relevante deveu-se ao fato de que o governo que se estabeleceu na Amazônia portuguesa não apenas foi distinto, do ponto de vista administrativo, do governo do Estado do Brasil como dele permaneceu separado por cerca de duzentos anos, conformando assim dinâmicas de gestão diferenciadas que, de modo usual, não se subordinavam àquelas aplicadas ao Estado do Brasil.

Entender as particularidades da Amazônia portuguesa significa problematizar a plasticidade da política imperial e, mais importante, o quanto ela foi pautada pelo movimento inverso ao da conquista. A experiência amazônica permite a avaliação do quanto as questões apresentadas pelas colônias foram determinantes para o dimensionamento da política imperial. Só a análise circunstanciada dos diversos processos vividos na região pode fazer emergir a singularidade daquela parte do mundo colonial e a potencialidade que ela guarda para a formulação de novas perspectivas de análise sobre a política imperial e sobre os limites de modelos explicativos que a assumem como determinada pelas necessidades da metrópole e não como resultado de uma negociação política.

Desde 1621, a Amazônia portuguesa constituiu um imenso território, reunindo conformações que acabaram por se mostrar distintas e diversas. As capitanias do Maranhão e do Grão-Pará compreendiam áreas tão vastas que ultrapassavam os limites do que hoje conforma a região norte. Densamente povoadas por povos indígenas, tais capitanias foram objeto de uma política indigenista singular e longeva que defendeu a incorporação daqueles povos à sociedade colonial. Da mesma forma, sua condição de área periférica do império viu emergir relações singulares, tão mais à revelia do controle administrativo do império quanto mais distante dos polos de irradiação do poder na colônia: Belém e São Luís. 
REVISTA DE HISTÓRIA

SÃO PAULO, N 168 , p. 16-23,

JANEIRO / JUNHO 2013
Patrícia Melo Sampaio e Mauro Cezar Coelho

0 Atlântico equatorial: sociabilidade e poder nas fronteiras da América portuguesa

O dossiê $O$ Atlântico equatorial: sociabilidade e poder nas fronteiras da América portuguesa problematiza as especificidades da colônia portuguesa naquela parte do império. A política indigenista implementada, a complexidade das políticas indígenas, a diversidade das trajetórias históricas de seus diferentes atores sociais, as relações havidas com os povos indígenas, as estruturas econômicas emergidas nos diferentes pontos da região, os conflitos políticos, entre outras instâncias da vida colonial, constituem as temáticas a serem debatidas. Por meio delas, o passado colonial amazônico pode ser percebido em sua singularidade e pode dimensionar a plasticidade da política imperial portuguesa, especialmente diante da diversidade e dos problemas apresentados por uma região cuja conformação geográfica e social demandava políticas próprias. E, ainda hoje, sua inteira compreensão se constitui em um dos grandes desafios deste país.

Antes de apresentar os artigos, consideramos ser necessário situá-los diante da produção historiográfica relativa a esta parte do Império português. Apesar de constantemente relacionada à natureza, o que constitui a Amazônia como espaço são (e foram) as pessoas que lhe atribuíram (e atribuem) significado. Apesar de óbvia, a assertiva é necessária a fim de dirimir eventuais surpresas diante do volume de referências acionadas pelos diversos autores. Desde o século XVII, intelectuais de origem e orientação variada se ocupam da compreensão da experiência colonial. A seguir, ensaiamos uma periodização.

Não se trata, evidentemente, de mera compulsão do ofício. O ensaio de periodização sugerido tem por objetivo situar os textos do dossiê, indicando o momento de sua produção, tendo a historiografia acerca da Amazônia portuguesa em perspectiva. Encaminhamos, então, um exercício de compreensão da historiografia voltada para a análise do Atlântico equatorial, suas singularidades e os nexos que os vinculam ao império. Acompanhe-nos.

A produção historiográfica relativa à Amazônia portuguesa pode ser situada em cinco momentos. O primeiro deles define o roteiro inicial das narrativas subsequentes. Nele, consubstanciou-se uma narrativa épica da conquista. Seus autores foram homens vinculados à estrutura administrativa do império, profundamente comprometidos com o processo de consolidação do domínio luso nessa parte do território americano conquistado da Espanha durante a União Ibérica. Bernardo Pereira de Berredo e Alexandre Rodrigues Ferreira foram os seus arquitetos.

O primeiro, governador do Estado do Maranhão, elaborou uma das primeiras narrativas sobre a conquista e a colonização da região. Seus Anais históricos do Estado do Maranhão abarcam tanto a chegada dos primeiros conquistadores quanto o estabelecimento das colônias e os conflitos envolven- 
do reinóis, americanos e indígenas. ${ }^{3} \mathrm{O}$ segundo, naturalista, protagonista da mais importante expedição científica durante a colonização portuguesa, construiu narrativas complementares às formuladas por Berredo. Alexandre Rodrigues Ferreira preocupou-se em expor a origem das vilas e lugares, em descrever os fortes, em ressaltar as relações mantidas com os povos indígenas. ${ }^{4}$ Ambos produziram uma história factual e narrativa, voltada para o engrandecimento e o destaque da ação portuguesa, envolvidos que estavam com a luta pela garantia do domínio português sobre o território conquistado à Espanha. ${ }^{5}$

O segundo momento pode ser relacionado às obras de três autores: Antonio Raiol, Manoel Barata e Teodoro Braga. Elas conformam o que, para muitos, constitui a historiografia clássica paraense. Enquanto os autores dos séculos anteriores pensaram a colonização como uma experiência de conquista, cujas disputas remetiam à Europa, estes homens do século dezenove se voltavam para o passado colonial buscando as origens da sociedade paraense e amazônica.

Essa pretensão não significou uma ruptura com o passado português. Não houve, nesse sentido, qualquer tentativa de consagração de heróis locais em oposição aos eleitos pela historiografia anterior. Os portugueses permaneceram como os protagonistas dos episódios escolhidos como demarcadores da trajetória histórica da região. Francisco Caldeira Castelo Branco, Pedro Teixeira, Antonio Vieira, Francisco Xavier de Mendonça Furtado, João Pereira Caldas, entre outros representantes da administração colonial, perduraram como os agentes históricos por excelência da história contada. Não obstante, uma inflexão pode ser percebida.

Menos do que o elogio à ação portuguesa foi a busca pelas raízes da sociedade paraense o que moveu esses intelectuais. Guardadas as especificidades e consideradas as pretensões de cada um, todos estavam envolvidos com

\footnotetext{
BERREDO, Bernardo Pereira de. Anais históricos do Estado do Maranhão. $2^{\mathrm{a}}$ edição. Florença: Typographia Barbera, 1905.

4 FERREIRA, Alexandre Rodrigues. Viagem filosófica ao Rio Negro. $2^{\mathrm{a}}$ edição. Organizada, atualizada, anotada e ampliada por Francisco Jorge dos Santos, Auxiliomar Silva Ugarte e Mateus Coimbra de Oliveira. Manaus: Edua/Editora do Inpa/Fapeam, 2007.

5 Um terceiro autor compõe esse primeiro momento da produção historiográfica. Trata-se de Antonio Ladislau Monteiro Baena. Ainda que tenha vivido e escrito em meados do século XIX, no contexto das lutas pela Independência (as quais se arrastam, na Amazônia portuguesa, até o final da primeira metade do século XIX), a narrativa histórica de António Baena é profundamente devedora das duas obras citadas. Em relação à experiência portuguesa, Baena segue os autores que lhe antecederam, consolidando, portanto, a perspectiva inaugurada por Bernardo Pereira de Berredo e Alexandre Rodrigues Ferreira. BAENA, Antonio Ladislau Monteiro. Compêndio das eras da província do Pará. Belém: Universidade Federal do Pará, 1969.
} 
REVISTA DE HISTÓRIA

SÃO PAULO, N 168 , p. 16-23,

JANEIRO / JUNHO 2013
Patrícia Melo Sampaio e Mauro Cezar Coelho

0 Attântico equatorial: sociabilidade e poder nas fronteiras da América portuguesa

o desvendamento das singularidades paraenses e das suas potencialidades. Os títulos de suas obras são muito sugestivos nesse sentido: História colonial do Pará, Ephemérides paraenses e História do Pará. ${ }^{6}$ Essa, desde onde percebemos neste ponto de nossas reflexões, é a inflexão promovida por esse momento: a eleição da região como protagonista importante da narrativa construída.

O terceiro momento é protagonizado por Arthur Cezar Ferreira Reis. Seguidor de Gilberto Freyre, este intelectual amazonense arvorou-se da gigantesca tarefa de integrar a região nos quadros da historiografia nacional. Sua produção é demarcada por duas matrizes: em primeiro lugar, o estabelecimento de nexos entre a história nacional e a trajetória histórica amazônica; em segundo lugar, a valorização do Estado como o principal promotor das inflexões políticas, sociais e econômicas havidas na região.

A noção de plasticidade é uma constante na obra de Arthur Reis. Enquanto Gilberto Freyre a atribuía aos portugueses, o historiador da Amazônia a estendia aos demais agentes que participaram da formação da sociedade amazônica. A região que emerge da obra de Arthur Reis é diversa como o Brasil e compartilha das mesmas matrizes africanas, europeias e indígenas. Não é, porém, neste único sentido que sua obra se integra à historiografia tida como nacional. Ela buscou articular-se aos estudos que buscaram perceber o sentido da colonização. ${ }^{7}$

Arthur Cezar Ferreira Reis produziu por cerca de cinquenta anos, de modo que o quarto momento da historiografia colonial acerca da América portuguesa não lhe é subsequente, mas concomitante. É nele, todavia, que se percebe a maior inflexão na produção historiográfica de que tratamos. Até aqui, a experiência colonial portuguesa na região é percebida como uma narrativa sequencial, em relação à qual se atribui um único sentido, demarcado pelos primeiros cronistas, ao tempo da colônia. Significativo, nesse sentido, é o fato de os estudos referidos até aqui basearem-se, fundamentalmente, em um conjunto restrito de fontes de natureza oficial - marcadamente, cronistas e representantes da Coroa.

\footnotetext{
${ }^{6}$ BARATA, Manoel. Formação histórica do Pará. Belém: Universidade Federal do Pará, 1973; BRAGA, Theodoro. Apostillas de historia do Pará. Belém: Imprensa Oficial do Estado, 1915; RAIOL, Domingos Antônio. Um capítulo de história colonial do Pará. Revista de Estudos Paraenses. Belém: Tip. do Diário Oficial. 1894.

7 REIS, Arthur Cezar Ferreira. A formação espiritual da Amazônia. São Paulo: SPVEA, 1964; Idem. A Amazônia que os portugueses revelaram. Belém: Secretaria de Estado da Cultura, 1994; Idem. A Amazônia e a cobiça internacional. Rio de Janeiro: Civilização Brasileira, 1982.
} 
REVISTA DE HISTÓRIA

SÃO PAULO, N $N^{\circ} 168$, p. 16-23,

JANEIRO / JUNHO 2013
Patrícia Melo Sampaio e Mauro Cezar Coelho 0 Atlântico equatorial: sociabilidade e poder nas fronteiras da América portuguesa

A produção subsequente introduz uma nova dimensão nas análises sobre a experiência colonial: o recurso a séries documentais, de natureza diversa, analisadas por meio de modelos conceituais que ensejavam a crítica às teses precedentes. Autores como Manuel Nunes Dias, Antonio Carreira, Ciro Flamarion Cardoso, Vicente Sales, Dauril Alden, Robin Leslie Andersen, David Sweet e John Hemming estabeleceram novas periodizações e inauguraram novos campos de pesquisa. ${ }^{8}$

Finalmente, o quinto momento. Estudos construídos desde a década de 1980 que, influenciados por essa última onda de trabalhos, aprofundaram a pesquisa documental e buscaram compreender outras nuances da vida colonial amazônica. Autores como Ângela Domingues, Antonio Porro, Auxiliomar Ugarte, Barbara Sommer, Décio Guzmán, Francisco Jorge dos Santos, José Alves de Souza Júnior, Maria Regina Celestino de Almeida e Nádia Farage $^{9}$ ampliaram enormemente o escopo documental das análises. Documentos provenientes dos arquivos da região, assim como aqueles disponibi-

\footnotetext{
8 DIAS, Manuel Nunes. Fomento e mercantilismo: a Companhia Geral do Grão-Pará e Maranhão, 2 v. Belém: Universidade Federal do Pará, 1970; CARREIRA, António. A Companhia Geral do Grão-Pará e Maranhão: o comércio monopolista Portugal-África-Brasil na segunda metade do século XVIII. São Paulo: Editora Nacional, 1988; CARDOSO, Ciro Flamarion S. Economia e sociedade em áreas coloniais periféricas: Guiana Francesa e Pará, 1750-1817. Rio de Janeiro: Graal, 1984; SALES, Vicente. O negro no Pará sob o regime da escravidão. Belém: IAP, 2005 (Programa Raízes); ALDEN, Dauril. O significado da produção de cacau na região amazônica, no fim do período colonial: um ensaio de história econômica comparada. Belém: UFPA/Naea, 1974; ANDERSON, Leslie Robinson. Following Curupira: colonization and migration in Pará, 1758 to 1930 as a study in settlement of the humid Tropics. Doctorate dissertation of Philosophy in History, University of California, Davis, 1976; SWEET, David G. A rich realm of nature destroyed: the middle Amazon valley, 1640-1750. PhD thesis, Madison, University of Wisconsin, 1974; HEMMING, John. Amazon frontier: the defeat of the Brazilian Indians. Londres: MacMillan, 1987.

9 DOMINGUES, Ângela. Quando os índios eram vassalos: colonização e relações de poder no norte do Brasil na segunda metade do século XVIII. Lisboa: Comissão Nacional para as Comemorações dos Descobrimentos Portugueses, 2000; PORRO, Antonio. O povo das águas: ensaios de etno-história amazônica. Rio de Janeiro: Vozes, 1995; UGARTE, Auxiliomar Silva. Sertões de bárbaros: o mundo natural e as sociedades indígenas da Amazônia na visão dos cronistas ibéricos (séculos XVI-XVII). Manaus: Editora Valer, 2009; SOMMER, Barbara A. Negotiated settlements: native Amazonians and Portuguese policy in Pará, Brazil, 1758-1798. Doctorate dissertation of Philosophy, History, University of New Mexico, Albuquerque, 2000; GUZMÁN, Décio. História de brancos: memória e historiografia dos índios Manao do Rio Negro (sécs. XVIII-XX). Dissertação de mestrado, Universidade Estadual de Campinas, Campinas, 1998; SANTOS, Francisco Jorge dos. Além da conquista: guerras e rebeliões indígenas na Amazônia pombalina. Manaus: Editora da Universidade do Amazonas, 1999; SOUZA JÚNIOR, José Alves de. Tramas do cotidiano: religião, politica, guerra e negócios no Grão-Pará dos Setecentos - um estudo sobre a Companhia de Jesus e a política pombalina. Tese de doutorado, Pontifícia Universidade Católica, São Paulo, 2009; ALMEIDA, Maria Regina Celestino de. Os vassalos d'el rey nos confins da Amazônia: a colonização da Amazônia ocidental, 1750-1798. Dissertação de mestrado, Universidade Federal Fluminense, Niterói, 1990; FARAGE, Nádia. As muralhas dos sertões: os povos indígenas no Rio Branco e a colonização. Rio de Janeiro: Paz e Terra; Anpocs, 1991.
} 
REVISTA DE HISTÓRIA

SÃO PAULO, N 168 , p. 16-23,

JANEIRO / JUNHO 2013
Patrícia Melo Sampaio e Mauro Cezar Coelho

0 Attântico equatorial: sociabilidade e poder nas fronteiras da América portuguesa

lizados pela digitalização de arquivos portugueses permitiram o vislumbre de dimensões insuspeitas da vida amazônica.

Os artigos que compõem o dossiê participam desse último momento. A experiência colonial não é percebida mais como um bloco único e homogêneo. Isto decorre, em larga medida, da diversidade da documentação pesquisada e dos procedimentos de investigação adotados - correspondências, devassas e atestações, por exemplo, não são percebidos mais como expressões de um real a ser alcançado, mas como apropriações das experiências vividas.

Rafael Chambouleyron e Vanice Melo analisam a expansão agropecuária nas capitanias do Maranhão e do Piauí. A análise proposta relaciona a conquista de novas áreas coloniais a uma conjuntura complexa, na qual se articulam as relações intraelites e delas com a Coroa, as relações havidas com os povos indígenas e eventuais surtos epidêmicos. Márcia Mello analisa a formação da pequena nobreza na Amazônia portuguesa, apontando as redes nas quais os agentes sociais se inserem e adquirem sentido. Simei Torres perquire o degredo como uma estratégia política do Estado português, com vistas à manutenção dos domínios ultramarinos. Na Amazônia portuguesa, os degredados foram incorporados às iniciativas de ocupação, controle e exploração do território colonial. Almir Diniz de Carvalho Júnior considera a inserção dos povos indígenas na sociedade colonial por meio da categoria "índios cristãos". Karl Arenz participa do dossiê apresentando a transcrição e tradução de um documento de autoria do padre luxemburguês João Felipe Bettendorff, superior da Missão do Maranhão. A carta situa as dificuldades da missão na Amazônia portuguesa e expõe as tensões que a Companhia de Jesus vivia em sua atuação no Império português. Seu artigo investiga as formas pelas quais os povos indígenas incorporados às unidades coloniais integraram-se às dinâmicas daquele novo universo sem deixar, no entanto, de impor limites às pretensões dos conquistadores. Mauro Cezar Coelho e Rafael Rogério Nascimento analisam o veredicto dos representantes da Coroa acerca da ação dos diretores das povoações do Diretório dos Índios. Conforme argumentam os autores, o que aqueles representantes percebem como desvios morais expressa, de outro modo, a emergência de poderes alheios aos interesses metropolitanos. Heather Roller perscruta a inserção de indígenas nas expedições de coleta das drogas do sertão. Seu artigo argumenta que o protagonismo indígena se manifestava na escolha por atividades garantidoras de certa autonomia, evidenciando a sua condição de agente histórico pleno, mesmo no interior da sociedade colonial. Juciene Ricarte Apolinário demonstra que as relações havidas entre a Coroa portuguesa e os povos indígenas não obedeceram aos princípios e projeções formulados. $\mathrm{O}$ 
REVISTA DE HISTÓRIA SÃO PAULO, N ${ }^{\circ} 168$, p. 16-23,

JANEIRO / JUNHO 2013
Patrícia Melo Sampaio e Mauro Cezar Coelho

0 Atlântico equatorial: sociabilidade e poder nas fronteiras da América portuguesa

interesse metropolitano em transformá-los em agentes defensores das fronteiras portuguesas não se concretizou sem negociações.

Ao analisarem as relações de poder e as sociabilidades recorrentes na fronteira equatorial da América portuguesa, os artigos aqui reunidos acusam algumas das singularidades da experiência colonial naquela porção equatorial do império. O primeiro aspecto a ser ressaltado é a distinção que aquela parte do território conquistado guarda em relação ao Estado do Brasil. A preponderância das atividades extrativas, a importância incontestável dos povos indígenas (tanto no que se refere à reprodução da matriz econômica, quanto no que tange à defesa do território) e a profunda maleabilidade da estrutura de poder (a qual, de um lado, demarcava vínculos com a Coroa e, de outro, balizava as relações internas, próprias da vida amazônica) vislumbram dinâmicas sociais singulares, próprias não apenas das regiões de fronteira, mas específicas da experiência equatorial amazônica. 